\title{
Application of Bio-Resorbable Membranes in Preventing Complications of Lower Jaw Surgery
}

\begin{abstract}
SUMMARY
Background/Aim: Prevention of inflammation and alveolar bone atrophy is very important in oral surgery. The aim of this study was to compare the use of two osteoplastic bio-resorbable membranes in order to prevent inflammatory complications and atrophy of the alveolar part of the mandible after surgical interventions. Material and Methods: We examined 86 patients 45-70 years old who were classified into four groups. In group 1 , there were 21 patients who had a "bio-resorbable membrane type 1 implanted. The group 2 consisted of 23 persons treated with bio-resorbable membrane type 2. Only the occurrence of inflammatory complications after the placement of these membranes was monitored. Group 3 included 20 persons treated with membrane type 1 and group 4 included 22 patients treated with membrane type 2 to prevent both inflammatory complications and atrophy of the alveolar part of the mandible. The level of atrophy of the alveolar bone after one year was determined by cone-beam computed tomography. The obtained data were statistically evaluated. Results: Six inflammatory complications ("dry socket") have been identified in operated patients treated with a membrane type 1 (the first and the third groups). Only two "dry socket" occurred in patients treated with membrane type 2 (the second and fourth groups). Group 4 had significant advantages in the alveolar crest height 14.6 (11.2-22.3) and in its width 7.7 (5.1-10.2) both in relation to the indices of group 3 (11.1 (9.7-20.4) and 6.2 (4.2-9.0). Conclusions: The bio-resorbable membrane type 2 prevented inflammatory complications in the short postoperative period after surgical interventions, as well as, the atrophy of the mandible.
\end{abstract}

Key words: Bio-resorbable membranes, Alveolar atrophy, Inflammatory complications, Mandible

\author{
Tušek Ivan ${ }^{1}$, Pohodenko-Chudakova Irina ${ }^{2}$, \\ Tserakhava Nikolaevna ${ }^{3}$, Maksimovich \\ Ekaterina $^{4}$, Karsyuk Yuri ${ }^{4}$, Savich \\ Alexander ${ }^{4}$, Mladenović Raša ${ }^{5}$ \\ ${ }^{1}$ Department of Pediatric and Preventive \\ Dentistry, Dental Clinic of Vojvodina, Faculty of \\ Medicine, Novi Sad Serbia \\ ${ }^{2}$ Belarusian Collaborating Center of European \\ Association for Cranio-Maxillo-Facial Surgeons, \\ Minsk, Belarus \\ ${ }^{3}$ Department of Pediatric Dentistry, Belarusian \\ State Medical University, Minsk, Belarus \\ ${ }^{4}$ Department of Oral Surgery, Belarusian State \\ Medical University, Minsk, Belarus \\ ${ }^{5}$ Department for Dentistry, Faculty of Medicine, \\ University of Pristina, Kosovska Mitrovica, \\ Serbia
}

\section{ORIGINAL PAPER (OP)}

Balk J Dent Med, 2022;1-6

\section{Introduction}

At the present time, the most common surgical interventions on the lower jaw are: tooth extraction; resection of the tooth root apex with subsequent curettage of periapical lesion; dental and atypical, complex removal of the third molar ${ }^{1-3}$. In addition, it is impossible to imagine a complete rehabilitation of dental patients with partial secondary edentulism, without prosthodontic structures based on dental implants ${ }^{3,4}$. At the same time, the use of the modern designs of dental implants with impeccable surgical technique, does not guarantee the absence of complications ${ }^{5,6}$, including inflammation ${ }^{7}$, with $9-35 \%$ of frequency according to the modern literature ${ }^{8}$. The inflammatory process developing in the mucosa (mucositis) is usually causing a severe destruction of bone tissue, directly adjacent to the dental implant (periimplantitis), leading to the loss of the dental implant in $52-57 \%$ of cases $^{8,9}$. It should be emphasized that a sufficiently large proportion of these complications are developing in the early postoperative period ${ }^{10}$. This is the subject for further research projects, developmental skills and the new improving methods of prevention. 
Everyday clinical practice shows that even in the absence of inflammatory complications, the width of the alveolar ridge after tooth extraction decreases during the first year from $25 \%$ to $50 \%$, i.e. $5-7 \mathrm{~mm}$. The greatest loss of alveolar bone (the two thirds of the volume) occurs about three months after tooth extraction. At the same time, a significant loss of bone tissue was observed in the vertical dimension, ranging from 0.9 to $3.25 \mathrm{~mm}^{11}$. Atypical removal of the third molar also results in a larger bone defect and consequent atrophy of the jaw ${ }^{12}$. This type of surgery is often complicated due to the lack of space in the alveolar part of the jaw bone or due to the retention and dystopia of the teeth. The condition can be aggravated if the bone tissue along the root and around the neck of the tooth is destroyed during tooth extraction, which latter indicate the presence of periodically exacerbation of infection and inflammatory process in the area. Prevention of alveolar bone atrophy is a particularly important issue for successful dental implantation ${ }^{11}$ and later prosthetic rehabilitation. Each of the above facts and all of them together, confirm the relevance of methods that reduce and diminish bone resorption after tooth extraction prior to implantation.

The aim of this study was to compare two bioresorbable osteoplastic membranes: membrane number 1 and membrane number 2 , in relation to the occurrence of complications after surgical interventions (tooth extraction, resection of the tooth root apex with cystectomy, etc.) and prevention of atrophy of the alveolar part of the mandible.

\section{Material and Methods}

The Ethics Committee of the Belarusian Research Committee of the State Medical University, protocol number 01-206-3/17, gave its consent for this research. The Ministry of Health has approved both bio-resorbable membranes for use in dental practice in accordance with the "Clinical Treatment Protocols". The patients gave informed consent for all surgical procedures. Two sophisticated bio-resorbable osteoconductive membranes: membrane type 1 ("Collapan") and membrane type 2 ("Collost"), which are often used in oral surgery in Belarus, were used in this research. The membrane type 1 (LTD Intermedapatite, Moscow, Russia) is a bioactive osteoplastic membrane that contains synthetic homogeneous hydroxyapatite powder, collagen type II and antimicrobial agent (lincomycin hydrochloride, colloidal silver, gentamicin sulfate, metronidazole, claforan, rifampicin, dioxidine). This membrane is approved and certified for clinical practice in the Republic of Belarus. The membrane type 2 (LTD Bopharma - holding, Moscow, Russia) contains a high - purity bovine collagen of type I and it is important to point out that its structure is completely preserved and original.

We examined 86 male patients, aged $45-70$ years old with indication for extraction teeth in lower jaw and with indication for preservation alveoli in later prosthetic rehabilitation. The study excluded persons with a history of decompensated diseases, injuries, surgeries that require medical rehabilitation, connective tissue diseases, oral pathology, as well as, other diseases that may have an impact on this research. Patients included in this study were classified into four groups. In the first phase of the research, a comparative analysis of the effects of two bio-resorbable membranes: membrane type 1 and membrane type 2 on the prevention of "dry socket" was performed (all four groups of respondents were included). The assessment was performed in the imminent postoperative period, after implantation of the membranes. The group 1 included 21 patients who were operated and the membrane number 1 was placed in the lower jaw. The group 2 consisted of 23 people who were treated with membranes number 2 during surgery. In order to prevent alveolar bone atrophy, a comparative analysis of membrane type 1 and membranes type 2 was performed in 20 patients in the third group and in 22 patients in the fourth group. Bio-resorbable membranes were used in accordance with standard methods ${ }^{13}$. After extraction the teeth we were elevation the buccal flap, and plated the membrane over alveoli of extraction teeth. After that we reposited and primary suture the flap. According to the surgical protocol, all patients received postoperative antibiotic ("Amoxicillin") and antiinflammatory ("Ibuprofen") treatment. Regarding the number of complications in the postoperative period, the effectiveness of the use of both bio-resorbable membranes was assessed. Based on the index of the bone tissue of the mandible, which was determined by cone-beam computed tomography (apparatus „Galileos“) the level of atrophy of the alveolar bone was counted after one year. Assessment of atrophy of the alveolar bone of the mandible was performed ${ }^{14}$ (Figure 1.):

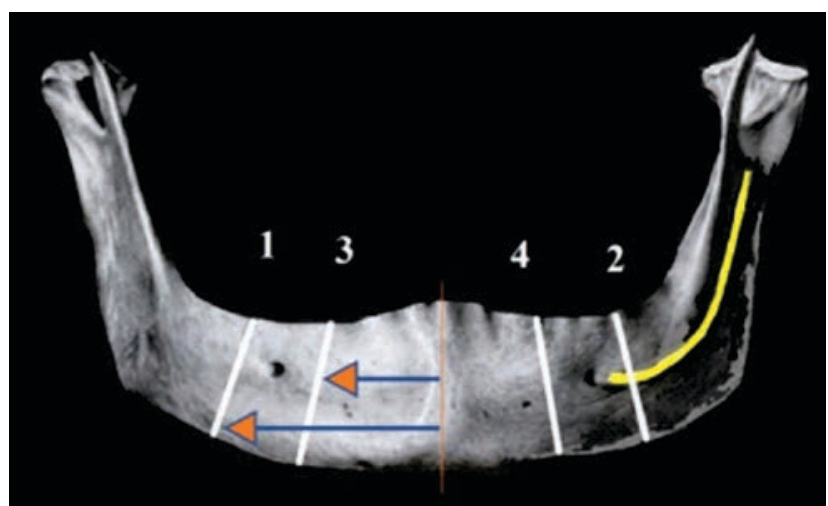

Figure 1. Measuring of the alveolar ridge of the mandibular height 
Symmetrical points 1 and 2 localized in the molar area (when determining points should focus on the location of the mandibular canal shown according to the radiological images); symmetrical points 3 and 4 localized in the inter-canine area

- in the area of the posterior teeth following the mandibular canal, at two points that are symmetrical. (Figure 1. - points 1 and 2 - average $17.8 \mathrm{~mm}$ );

- in the area of the anterior teeth following the line of the canines, at two symmetrical points. (Figure 1. points 3 and 4 - average $43.6 \mathrm{~mm}$ )

The obtained data was statistically processed using the computer program "Statistica 10.0" (Version 6 - Index, Stat Soft Inc., USA). Before using descriptive statistic method, the type of distribution of quantitative traits was determined using the Shapiro - Wilk criterion. The arithmetic mean $(\mathrm{Me})$ and standard deviation $(\sigma)$ were calculated for the features with normal distribution. The significance of the statistical differences between the dependent groups was evaluated with the Wilcoxon test and Friedman's analysis of variance. The Mann-Whitney (U) test was used to determine statistical significance between unrelated groups. Bonferoni correction ( $p$ $\mathrm{x}$ number of comparisons) was used for multiple comparison of groups. The student $\mathrm{T}$ test was used to compare the features of the examined groups ${ }^{15,16}$.

\section{Results}

The distribution of patients in the follow-up groups regarding verified diagnoses where osteoplastic bioresorbable membranes were used are presented in Table 1.

It can be concluded that the largest number of operated patients (62) were diagnosed with "Posterior mandibular teeth with periapical lesions", followed by 13 patients with the diagnosis "Impacted lower third molars" and 11 patients with the diagnosis "Radicular cyst in the anterior mandible".

Table 1. Distribution of the patients regarding the diagnoses

\begin{tabular}{|c|c|c|c|c|c|c|c|c|}
\hline \multirow[t]{2}{*}{ Diagnoses } & \multicolumn{2}{|c|}{$\begin{array}{c}\text { Group } 1 \\
\text { with } \\
\text { membrane type } 1\end{array}$} & \multicolumn{2}{|c|}{$\begin{array}{c}\text { Group } 2 \\
\text { with } \\
\text { membrane type } 2\end{array}$} & \multicolumn{2}{|c|}{$\begin{array}{c}\text { Group } 3 \\
\text { with } \\
\text { membrane type } 1\end{array}$} & \multicolumn{2}{|c|}{$\begin{array}{c}\text { Group } 4 \\
\text { with } \\
\text { membrane type 2 }\end{array}$} \\
\hline & $\mathrm{N}$ & $\%$ & $\mathrm{~N}$ & $\%$ & $\mathrm{~N}$ & $\%$ & $\mathrm{~N}$ & $\%$ \\
\hline Radicular cyst in the anterior mandible & - & - & - & - & 5 & $5.81 \%$ & 6 & $6.98 \%$ \\
\hline $\begin{array}{l}\text { Posterior mandibular teeth with periapical } \\
\text { lesions }\end{array}$ & 21 & $24.42 \%$ & 23 & $26.74 \%$ & 9 & $10.47 \%$ & 9 & $10.47 \%$ \\
\hline Impacted lower third molars & - & - & - & - & 6 & $6.98 \%$ & 7 & $8.14 \%$ \\
\hline
\end{tabular}

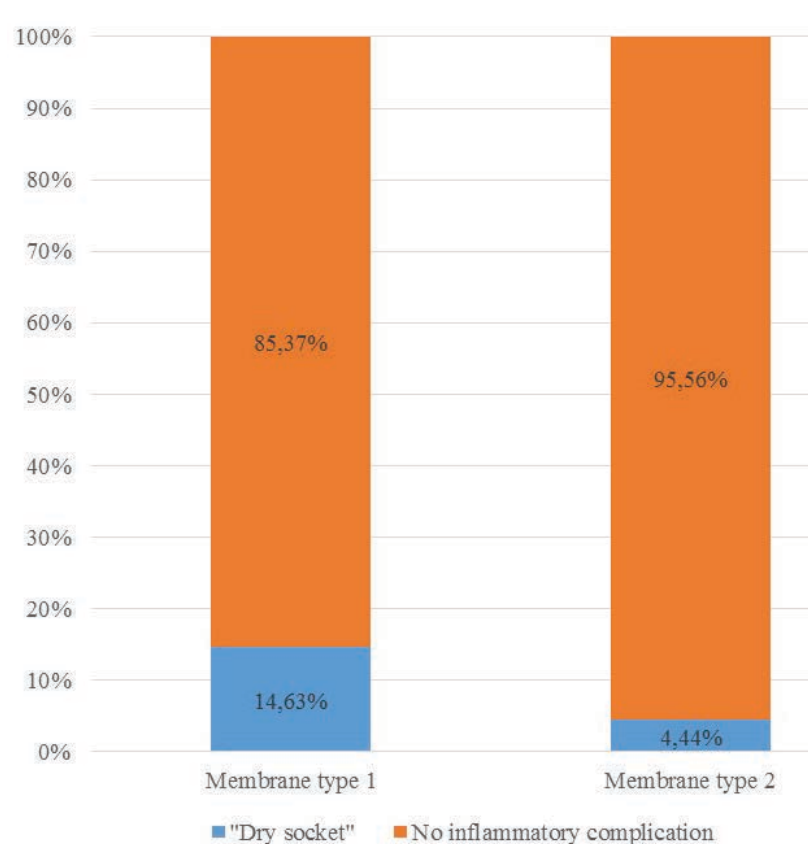

Figure 2. Occurrence of infectious-inflammatory complications ("dry socket") in patients treated with membrane type 1 and membrane type 2
Of the 41 operated patients treated with bioresorbable membrane type 1 (the first and the third groups), six (14.63\%) inflammatory complications ("dry socket") were observed; two complications occurred after extraction of impacted lower third molars, and four complications after difficult extractions of lower molars with curettage of periapical lesion (Figure 2). Only two (4.44\%) inflammatory complications ("dry socket") occurred in 45 patients treated with membrane type 2 (the second and the fourth groups); one after removal of the impacted lower third molar and one after difficult extraction of premolar tooth with curettage of periapical lesion.

Table 2 shows the results in relation to the change in height and width of the alveolar part of the mandible one year after the application of membrane type 1 and bio-resorbable membrane type 2 only in patients from the third and fourth groups (the second phase). The measurement results indicate a greater preservation of mandibular bone volume, in the group of patients treated with type 2 membrane, compared to the group of patients treated with type 1 membrane (Table 2). 
Table 2. Atrophy of the alveolar ridge of the mandible one year after surgery

\begin{tabular}{lcc}
\hline $\begin{array}{l}\text { The alveolar part of } \\
\text { the mandible } \\
\text { (The indices) }\end{array}$ & $\begin{array}{c}\text { Patients treated } \\
\text { with membrane } \\
\text { type 1 }\end{array}$ & $\begin{array}{c}\text { Patients treated with } \\
\text { membrane type 2 }\end{array}$ \\
& $\begin{array}{c}\text { Group 3 } \\
(\mathrm{n}=20)\end{array}$ & $\begin{array}{c}\text { Group 4 } \\
(\mathrm{n}=22)\end{array}$ \\
\hline The height $(\mathrm{mm})$ & $\begin{array}{c}11.1(9.7-20.4) \\
\sigma^{*}= \pm 2.0\end{array}$ & $\begin{array}{c}14.6(11.2-22.3) \\
\sigma= \pm 2.2\end{array}$ \\
& $6.2(4.2-9.0)$ & $7.7(5.1-10.2)$ \\
The width $(\mathrm{mm})$ & $\sigma= \pm 0.7$ & $\sigma= \pm 0.9$ \\
\hline
\end{tabular}

$\sigma^{*}=$ standard deviation

\section{Discussion}

In the process of wound healing after surgery (tooth extraction, apicotomy, curettage of periapical lesion, etc.), remodeling and atrophy of the alveolar bone occur, which makes it difficult to install dental implants later $^{17}$. In recent years, the development of various bioresorbable and non-resorbable membranes has been intensive, as well as their use in oral, periodontal and maxillofacial surgery. Two types of bio-resorbable membranes are used in clinical practice: natural ones made of collagen or chitosan and synthetic ones made of aliphatic polyesters and copolymers. The good characteristics of bio-resorbable membranes are: one-step procedure, the shape and volume of regenerated bone can be determined preoperatively, they are radiolucent, and their biodegradation eliminates ,stress shielding effects of the regenerated bone ${ }^{18}$. Bio-resorbable membranes are often used in oral surgical procedures due to their positive osteoinductive and osteoconductive characteristics that prevent local atrophic processes and accelerate the processes of bone tissue repair and regeneration. The ability of collagen is to stimulate chemotaxis, adhesion, physiological degradation of progenitor cells, as well as auto degradation, making it a suitable material for building membranes. Commercial collagen products available today usually consist of type I and III collagen. In our research, we used a bio-resorbable membrane containing collagen type 2 (Collapan), which is more often used in Belarus and Russia than in other European countries. In the process of guided bone regeneration, it has been shown to have weak immunogenicity, to cause hemostasis and can increase tissue thickness ${ }^{19}$. Research by Sbricoli et al. ${ }^{20}$ have shown that the main weakness of native collagen membranes are poor mechanical characteristics which can lead to its intrusion into a bone defect. To avoid this, it is necessary to combine the collagen membrane with the bone graft or to improve its characteristics ${ }^{20}$. The most commercial bio-resorbable membranes today are made of collagen (Biomend, Biomend Extend, Copios Extend, Osseoguard, Bio Gide). Collagen membrane has been shown to stimulate fibroblast DNA synthesis, with osteoblasts showing a high level of adhesion to its surface. The biodegradation of collagen membranes takes place by endogenous collagenases into carbon dioxide and water ${ }^{21}$, where the rate of its degradation can vary and be adapted to the time required for proliferation and maturation of the desired cells within the wound. The collagen membranes that are currently available on the market allow the surgeon to choose the membrane that suits him in relation to the different resorption time and the size of the bone defect. The collagen membrane should allow for primary tension - free wound closure, adequate angiogenesis, space maintenance to create space for the development of undifferentiated mesenchymal cells, and clot stability. Proper indication as well as adequately applied surgical technique reduces the possibility of inflammatory complications. ${ }^{19}$.

The number of inflammatory complications in our study is low, which is in line with our previous research ${ }^{22}$. Comparing the anti-inflammatory effect of the used bioresorbable membranes, about three times less number of infective complications was observed when using the membrane type 2 compared to membrane type 1 . Similar research by Pohodenko et al. $^{22}$ confirms our results, pointing out that a larger number of inflammatory complications $(28 \%)$ were observed in patients who were not treated with membrane type 1 and membranes type 2 after surgery. However, Shevela et al. ${ }^{23}$, believe that „dry socket“ can occur after postoperative treatment (tooth extraction) when a blood clot is washed out of the alveoli during mouth washing, with microorganisms of the oral cavity penetrating it and causing its inflammation. Also, food entry into the post extraction wound as well as poor oral hygiene can also be an etiological factor. It is most likely that the high degree of biological integration in the tissue of the operated person with the low antigenicity of the material itself led to the absence of the inflammatory response of the oral mucosa when applying the membrane. It is important to emphasize that after the application of both types of membranes, special attention is paid to oral hygiene because it has been proven that certain types of oral microorganisms such as Porphyromonas gingivalis and Bacteroides melaninogenicus accelerate the degradation of collagen membranes ${ }^{19}$. Protective collagen membranes play an important role in regeneration, bone remodeling, as well as promoting wound healing after surgery ${ }^{20}$.

Our study emphasizes the advantage of using the osteoconductive bio-resorbable collagen membrane "Collost" for the prevention of atrophy of the alveolar cavity of the lower jaw, which is in accordance with the reports of Seliverstov et al. ${ }^{24}$ Medvedev et $a l .^{25}$ The explanation for this result lies in the fact that the 
membrane type 2 is made of a natural protein (collagen type I) that easily binds various drugs, including antibiotics $^{26}$. Our results show that postoperative administration of anti-inflammatory drugs significantly increases regeneration and reduces atrophy of the alveolar ridge of the mandible after implantation of the membrane type 2 in the long terms period of observation. It corresponds to the information provided in the literature ${ }^{24,26}$. Recently, Turri et al. showed that collagen membranes attract cells that secrete signals for bone regeneration and reshaping, and thus promote the expression of chemotoxic factors, modulating the osteogenic process ${ }^{27}$. Also, the collagen membrane can adsorb growth factors released from bones and cells and improve guided bone regeneration. The collagen bioresorbable membrane shows good interaction with soft tissues, enabling greater oxygen exchange, microelement passage and blood perfusion, and favours cell proliferation and differentiation ${ }^{28}$. Despite numerous evidence-based efforts to preserve alveolar bone, minimal vertical bone resorption has been found to be unpredictable. Although there are positive results in the prevention of horizontal resorption of the alveolar ridge, further research is needed to prevent vertical resorption of the alveolar part of the mandible ${ }^{29,30}$. Depending on the indication, the size of the defect in the bone, the location of the defect, etc., surgeons will choose the procedure and type of membrane that will give the best results in relation to atrophy of the alveolar ridge of the mandible and the possible occurrence of inflammatory complications.

\section{Conclusions}

Based on the results of our research presented in this paper, it can be concluded that in order to prevent inflammatory complications in the imminence postoperative period after outpatient surgical interventions on the alveolar part of the lower jaw, as well as, to prevent later atrophy, it is most advisable to use an bio-resorbable membrane type 2. The use of this membrane enables later more successful prosthetic rehabilitation based on dental implants and may allow better quality of life of this category of the patients.

\section{References}

1. Pohodenko-Chudakova IO, Barmutzkaya AZ. Prevention of complications of acute odontogenic infection at the present stage. Stomatologist, 2010;1:20-23.
2. Iordanishvili AK, Ponomarev AA, Korovin NV, Gayvoronskaya MG. Frequency and structure of complications after removed of mandibular wisdom teeth. Bashkortostan Med J, 2016;11:71-73.

3. Storelli S, Del Fabbro M, Scanferla M, Palandrani G, Romeo E. Implant supported cantilevered fixed dental rehabilitations in partially edentulous patients: Systematic review of the literature. Part I. Clin Oral Implants Res, 2018; 29:253-274.

4. Starch-Jensen T, Jensen JD. Maxillary Sinus Floor Augmentation: a Review of Selected Treatment Modalities. J Oral Maxillofac Res, 2017;8:e3.

5. Bazaeva IK, Lalieva ZV. Prevention of complications of dental implantation. Proceedings young scientists of Vladikavkaz scientific center of RAS. 2015;15:47-53.

6. Shi B. Aesthetic complications of immediate implant placement of anterior teeth. Zhonghua Kou Qiang Yi Xue Za Zhi, 2018;53:810-814.

7. Chen W, Zhi M, Feng Z, Gao P, Yuan Y, Zhang C, et al. Sustained co-delivery of ibuprofen and basic fibroblast growth factor by thermo sensitive nanoparticle hydrogel as early local treatment of peri-implantitis. Int J Nanomedicine, 2019;21:1347-1358.

8. Garayev ZI, Javadov RA, Nasirova XB. Reduction of the ric of complication at the dental implantation. Sovremennaya stomatologiya, 2014;2:74-76.

9. Ushakov AR, Ushakov RV, Dautov HR, Korkin VV. The frequency of infectious and inflammatory complications after dental implantation. Proceedings of the VIII Internat Sci and Pract Conf Belgorod: Publishing house "Belgorod", 2015;290-294.

10. Яров Ю. Обоснование схем поддерживающего лечения после дентальной имплантации. Вестник стоматологии, 2013;4:63-68. (in Russian)

11. Andreasi BM, Andrisani C, Lopez MA, Gaudio RM, Lombardo L, Carinci F. Guided bone regeneration by means of a preformed titanium foil: A case of severe atrophy of edentulous posterior mandible. J Biol Regul Homeost Agents, 2016;30:35-41.

12. Fickl S, Fischer K, Petersen N, Happe A, Schlee M, Schlagenhauf U, et al. Dimensional evaluation of different ridge preservation techniques: arandomized clinical study. Int J Periodontics Restorative Dent, 2017;37:403-410.

13. Минина АH, Чернина ТН. Основы дентальной имплантации: Учебно-методическое пособие. Витебск: УО «Витебский государственный медицинский университет; 2013. (in Russian)

14. Lazarenko AV, Kan VV, Terskih SA. Assessment of jaw bone parameters in patients of retirement age with complete and partial absence of teeth. Kuban Sci Med Bull, 2015;151:93-97.

15. Rebrova OY. Statistical analysis of medical data. Application of „Statistica“ application software package. Moscow: Media sphere; 2002. (in Russian)

16. Gerasimov AN. Medical statistics. Moscow: Medical Information Agency; 2007. (in Russian)

17. Avila-Ortiz G, Chambrone L, Vignoletti F. Effect of alveolar ridge preservation interventions following tooth extraction: A systematic review and meta-analysis. J Clin Periodontol, 2019;46:195-223. 
18. Dimitriou R, Mataliotakis GI, Calori GM, Giannoudis PV. The role of barrier membranes for guided bone regeneration and restoration of large bone defects: current experimental and clinical evidence. BMC Med, 2012;10:81.

19. Bubalo M, Lazić Z, Tatić Z, Milović R, Magić M. The use of collagen membranes in guided tissue regeneration. Vojnosanit Pregl, 2017;74:767-772.

20. Sbricoli L, Guazzo R, Annunziata M, Gobbato L, Bressan E, Nastri L. Selection of Collagen Membranes for Bone Regeneration: A Literature Review. Materials (Basel), 2020;13:786

21. Bunyaratavej P, Wang HL. Collagen Membranes: A Review. J Periodontol, 2001:72;215-229.

22. Pohodenko-Chudakova I, Tserakhava T, Maksimovich $\mathrm{K}$, Zenkevich Y. Complication rate of osteoconductive membranes over fresh alveolar sockets. Stoma Edu J, 2017;4171-4174.

23. Shevela TL, Pohodenko-Chudakova I, Groshev EY. Results for modern bandaging materials application in alveolitis treatment. Engineering of Biomater, 2011;14:13-14.

24. Seliverstov DV, Kuznecov AV, Maskvnin VV, Kondrus' IV, Novikov LA, Judin VA. The use of biological material "Collost" in the complex surgical treatment of pressure sores of IV degree. Rus Med J, 2015;13:776-780.

25. Medvedev YuA, Dyachkova EYu. The surgical treatment of patients with jaw defects after removing teeth based on the utilization of osteoplastic material "Collost". Int Rev Clin Practice and Health, 2015;6:38-45. (In Russian)

26. D'Amato S, Tartaro G, Itro A, Santagata M. Mandibular bone regeneration after bone slat tehnique. Ann Stomatol, $2017 ; 8: 39-44$.
27. Turri A, Elgali I, Vazirisani F, Johansson A, Emanuelsson $\mathrm{L}$, Dahlin C, et al. Guided bone regeneration is promoted by the molecular events in the membrane compartment. Biomater, 2016;84:167-183.

28. Thoma DS, Bienz SP, Figuero E, Jung RE, Sanz-Martín I. Efficacy of lateral bone augmentation performed simultaneously with dental implant placement: A systematic review and meta-analysis. J Clin Periodontol, 2019;46:257-276.

29. Lee HJ, Kim MJ, Kim YK, Yun PY. Extraction socket preservation using $\beta$-TCP coated with recombinant human BMP (rhBMP-2): randomized clinical prospective study. Oral Biol Res, 2011;35:110-115.

30. Jeong HJ, Gwak SJ, Seo KD, Lee S, Yun JH, Cho YS, et al. Fabrication of Three-Dimensional Composite Scaffold for Simultaneous Alveolar Bone Regeneration in Dental Implant Installation. Int J Mol Sci, 2020;21:1863.

Conflict of Interests: Nothing to declare.

Financial Disclosure Statement: Nothing to declare.

Human Rights Statement: All the procedures on humans were conducted in accordance with the Helsinki Declaration of 1975, as revised 2000. Consent was obtained from the patient/s and approved for the current study by national ethical committee.

Animal Rights Statement: None required.

Received on February 24, 2021.

Revised on April 28, 2021.

Accepted on Jun 20, 2021.

\section{Correspondence:}

Raša Mladenović

Faculty of Medicine, Department for Dentistry

University of Pristina, Kosovska Mitrovica, Serbia

e-mail: rasa.mladenovic@med.pr.ac.rs 